PART 2

UNDERSTANDING INDIVIDUAL LEARNING AND LEARNING CAREERS IN LIFE HISTORY 


\title{
4. AGGRESSION, RECOGNITION AND QUALIFICATION
}

\author{
On the Social Psychology of Adult Education and Learning \\ in Everyday Life
}

\section{FROM “WIDER BENEFITS” TO “ACKNOWLEDGED COMPLEXITY”}

Adult education can surely be shown to possess a number of "wider benefits" for individuals, employers and society. A cool-headed academic approach should, however, not jump to such demonstration without reflecting on the nature of more traditional benefits - such as motivation and learning. The historical framework for giving substance to the benefits of education are more complex than ever before, as current internationalisation and (discourse of) globalization does indeed point to. Education is not about skills and qualifications only, but about identities and lifelong development of capacities and attitudes. And is it, one may ask, subjectively exclusively a benefit to engage in such processes? Even in Denmark, who possesses a well developed system of general and labour market education, motivations are not always so positive as the tradition of enlightenment would assume.

For the structural paradoxes behind the expanding and programmatically optimistic adult education sector are of course perceived more or less directly by participants. In Denmark we empirically register considerable enthusiasm about education - often with women - or downright refusal of it - often with men, if the training in question is not directly relevant for work or employment. Below the surface more mixed and complex motivations can generally be found, and in this chapter I shall indeed focus on two populations, whose subjective motivations for participating in their respective formally qualifying educational programmes were certainly explicitly ambivalent both cognitively and emotionally. And whose contradictory motivations were constituted by perceptions and experiences deeply personal and individual, yet collective and historically significant. This chapter was written for the ESREA triennial conference "Wider Benefits of Adult Learning" in Lisbon 2001.

\section{EMPLOYMENT DEMANDS EDUCATION}

So my empirical material, the texts to be discussed, are two. One is produced in a thematized group discussion by a group of adult men - long term unemployed skilled workers along with ex-UN soldiers out of a civil job - who went through 
a two year training programme for jobs within care. They did so with a view to obtain permanent employment as wardens in a psychiatric hospital - by tradition a man's job. The other text is produced in a group interview by a mixed gender group of adults working in youth clubs - but not possessing any formal qualifications within social pedagogy. They completed a two year part time programme especially designed to match their job, which they kept during the entire period of training, but which they would lose if they did not complete the training.

Both texts were produced as empirical data in evaluation projects concerning the respective educational programmes. ${ }^{1}$

So the empirical populations are exemplary objects of the current function of adult education which is to not only supply the qualifications allegedly needed in the jobs available, but to furthermore constitute the space where fundamental changes of work identity and general future orientation may develop. The subjective journeys of the skilled painter or welder and his class-mate, the soldier just returned from Kosova, towards identification with the professional standards of the caring professions - and the shifts of life perspective of the hairdresser towards becoming a social worker, are considerable ones.

So the explicit ambiguities voiced to the researchers ${ }^{2}$ were to be expected. Both groups - and their colleagues - had good reason to be concerned about their future employment, income and social status. They were explicitly dependent on the specific economic organization, designed to keep them on track, of their programmes. The instrumental attitude was forever popping up ... interrupting and disturbing the agreed agenda, which was that of subjectively relevant and societally demanded qualification. Much fussing and complaining in the texts can be attributed to the labourious psychological processes harmonizing the basically compulsory participation with the self-identity as autonomous adults, of managing the competing motivations of infantilisation and boredom versus the obviously interesting - at least occasionally! - substance of the educational discourse and the subjective need to attribute some kind of meaning to the perspective of doing this job for a considerable number of years, if not for the rest of one's life.

The fact that the educational programmes were subject to evaluation probably accentuated the perception of this implicit motivational conflict. ${ }^{3}$ The participants did not think of themselves as contributors to educational evaluations or to any other major political problems, and anyway the message to research subjects ${ }^{4}$ is always a double one: in the context the research subjects are the most important people on earth, the chosen, those receiving attention - while at the same time they might immediately and with no special effect on the research agenda be substituted by somebody else. ${ }^{5}$

The subjective conflict outlined is interesting and its analysis can yield considerable inspiration to improvement or renewal of educational settings. The focus of this particular analysis, however, is on a number of "uncouth" outbursts of aggression, on collectively agreed statements about others, that were surprising and disquieting even in the relaxed and permissive context of research interviewing and discussion. 
It may be argued that such outbursts belong to ordinary human communication and that they should be condoned. Every text production comprises irrelevancies, and is it not the function of the researcher to sort this out, to get the discussion back on the track, to condense the objective and impartial? In my approach: Not necessarily so! The very organization of the research group building on existing social organization aims at bringing out the explicit as well as the implicit substance and the legitimate as well as the illegitimate psychological energies immanent in the social setting. The presupposition is that "thinking is a highly emotional affair" (Becker-Schmidt, 1987), that factual and functional attitudes and opinions are products of multidimensional subjective processes that are cognitive, social, emotional as well as physical - and furthermore that the group processes contribute to the exposition of this complexity. The irrational, even the idiosyncratic, surplus is an invaluable spur to research. This is a point highly relevant for our conceptions of learning, e.g. in that it approaches the everyday situation in education where teachers and administrators often face diffuse complaint (cf. Weber, 2001b). I shall return in some detail to the theoretical framework, once I have presented the texts and my provisional analyses.

\section{THE BODIES IN THE DEPARTMENT - ON THE PERCEPTION OF FEMALE SUPERIORS}

During the thematized group discussion on the qualities of work - taking place immediately after a practice period in the hospital departments - life the following passage $^{6}$ occurs. It is one out of many where the perception of women become the defining theme of the discussion, and where the men in education for social- and health assistants denounce their female colleagues whose "cunt prat" or "cucumber cackle" they overtly and explicitly detest:

Steen: "Is there anything you've been provoked by, when you got out [in the departments of the hospitals KW]?"

Mads: "That the women have so much power. It scared me somewhat in the first place [I was in KW]. There were two men there, and I saw very little of them, and the rest ... they were women. It's just $a$ bit strange, to sit there, among all those women, and to hear nappy-talk, and birthings, and all the time, you know, that sort of thing ...".

Lars: "Exactly!"

Mads: "Like food recipes, clothes and make-up. It's simply impossible to join in. A man might as well keep his mouth shut".

Steen: "So there is a culture in the place that you feel you don't belong to?"

Mads: "But, yes, you know, I would actually like to talk. They are very nice, the women are, but it sort of scares you a bit, that there are just so many women 
sitting there, you ... you don't really have anything grand to contribute, you know ... at least I feel I don't".

Lars: "I'll certainly confirm that ... when they sit around talking about how sore their nipples are ... from breast-feeding, you know."

Loud laughter around the table.

Peter: "Well, I was thinking, that it's something that affects the patients, these things, when we were talking about all that cuckoo ...".

Several people make confirming noises.

Peter: "I said: "Actually, you know, it might have benefited the patients, all this time here!" ... just wasting away every morning. All year round. Year out and year in. There's a bloody lot of resources there that just ... and fuck the patients anyway".

Lars: It's also because there are some departments that are very particular about it, that now we have a break, isn't it? "Now we cannot talk anymore!" And it's psychiatric people around here, people that you cannot just treat like that, I feel".

Peter: "Like "Please hurry up and eat up, so that we can lay the table for us!". That way, that there attitude, I really can't stand".

Lars: "I remember that I was obliged to hold my breaks along with the rest of the regular staff. In that there women's department that I was in. Erh ... and a ... we only had that half hour break the whole day. And a, it [the work KW] was all about sitting and drinking coffee and chatting with patients and the like. And then, you know, I liked it, to go upstairs to play table tennis [with patients $\mathrm{KW}$, in order to, sort of, get some exercise, you know. It was rather nice, you know, to just, like ... instead of sitting down all the time. But they wouldn't have that. I was to sit down and have my break along with the rest of them, because, as they put it, it was about ... and it did happen too, that they talked about patients, and the like. So it was important that we were there".

Peter sighs audibly.

Lars: "But I never experienced, not once, that the actually did talk about patients. It was always about those, well ... those women's things".

\section{Facts and Fiction}

If we look first at the factual content of the passage the first striking thing is the very first reply by Mads, the willing admission that the most provoking thing about practice periods in psychiatric departments is not the psychiatric patients, the sometimes violent confrontations, the strenuous working conditions and night shifts - but "that 
the women have so much power". The general idea of the health sector is that the medical profession, the doctors, occupy the executive layers of the organization, both administratively and medically, and the statistical truth is that doctors are most often men. ${ }^{8}$ The next striking thing is that the concrete exemplification of the alleged exertion of power is women who sit and talk - in general cultural terms that is the most powerless of images! Sitting, not moving; talking, not acting; selfcontained, not directed against others. Furthermore the power talk is about children and childbirth - the latter certainly in a fundamental sense a powerful thing, but as a topic of conversation one could hardly think of a less belligerent one.

Further on in the passage a number of allegations are made about the staff wasting a lot of time on their job, not caring about the patients, being overly obsessed with negotiated rights such as regular breaks, and even being bossy towards patients as well denying trainees their breaks and lying about their professional commitment, alleging to speak professionally when in fact they are chatting about themselves. Of course we are in no positions to deny that these accusations may be true, but the assembled recriminations seem more fit for a political vendetta against the growing public sector than for a discussion of the learning experience of would be social and health assistants. Which is what is actually is.

On the other hand the passage conveys a culturally plausible image of female work place culture, which is indeed what the interviewer hears and interprets as an experience of exclusion on behalf of the men. This active definition of the initial tale is accepted - even to the degree that the men state their own innocence: they do want to talk! And to the degree that examples of explicit humiliation is given: a man has been denied the right to stand up and leave the table, he has been put in his place as if he were a child.

So on the referential level the passage is about women who talk about women's things and who do their job poorly, and about oppression and humiliation of men by women.

\section{Communicative Dimensions}

As the transcription hopefully communicates the passage was spoken with dedication and eagerness. Mads' opening answer is somewhat reluctant, only speeding up towards the end. The "somewhat scared" and the paradoxical "a bit" (strange) in fact means very much so, and furthermore Mads' comes up with a proper linguistic innovation the the phrasing of "birthings" thus stressing the strange quality of the situation, attributing a connotation of active giving birth, instead of just referring to childbirths as events of the past, and maybe even signifying that - at least for him new experience is being formed in the situation. His experience is immediately confirmed (by Lars), elaborated ("food recipes, clothes and make-up") and followed up (by Lars: "sore nipples", "breast-feeding"). Later on the example of the female staff disregarding the patients is about taking the space for their own eating, and the 
scene where their power is exerted towards the trainee is that of "sitting and drinking coffee".

So the general characterization of the women's talk has to do not only with activities that are culturally connotated as belonging to a women's realm of experience, it also specifically about body, reproduction (babies sucking, women eating and drinking, food-recipes, babies' faeces), intimacy (mother-child dyade, sore nipples), and decorating the body (clothes and make-up) with a view to looks and possible seduction.

The general perception of the women is of their number (all those women, so many women), power and possession of space (the women's department) and the notion of their (in)activities is its all-consuming nature (all that cuckoo, all this time, every morning, all year round, day in and day out, bloody lot of resources, all about sitting and ..., sitting down all the time) - concerned about themselves.

The general image of the men, on the contrary is that they are few, and not seen, that they might as well keep quiet, and that they do not have anything grand to contribute (or feel they don't). When Peter introduces the patients' perspective he not only offers a rational and professional framework for the dissatisfaction of the men, he directly inverts the psychologic states of the staff and the patients in that it's the staff's talk that is "cuckoo", not the psychiatric patients. Who are, in their turn, "affected", need the "time to benefit them", are degraded and neglected, and who "cannot just be treated like that". In short, the patients are characterized as suffering much in the same way as the men themselves, and their liberty to move about are even envied and sought for (in joining the table tennis).

As the men are thus denied their space they focus on and specify what they are not able to do: they are not able to contribute anything grand (as implicitly a man should presumably do) and they are not allowed to be physically active (rationalized into "getting some exercise" by Lars. As a result they are left to allege that they'd like to talk (i.e. do as the women do), to feel, to think, to be there. Paradoxically, what happens in the group discussion is actually that the men adopt the female standard of talking about themselves as well as mutually confirming their professional interest taking on what is formally the women's obligation.

The conclusion of the passage holds special interest: The statement that the female staff is basically not concerned with their work "not once did they talk about the patients" is a direct contradiction of the preceding "it did happen too, that they talked about patients, and the like". The self-contradiction is triggered off by the colleague Peter's non-verbal reply. Peter's sigh seems to imply "they would say that, wouldn't they". The reference disturbs the by now established rational message and the shared emotional content of the communication immediately causes it to be censored.

\section{Threatening Femininity}

During the passage the emotional experience of being threatened, excluded and belittled, as well as being exposed to women's intimacies, is supplemented by a 
rational and professional concern about the patients. In the context, however, it is obvious that the patients are not analysed in their own right, but serve as objects of projection of the men's own perceptions and needs. The total image is that of the men being surrounded by and engorged by female passive-active flesh to an extent that it becomes necessary to break away, to get up and out. If the interpretation of the men collectively wishing to be reborn out of this institutionalized womb, the perceptual version of the scene of their labour market integration, is perhaps a dramatic one, it is, none the less, the one that emerges to the empathic reader sympathising with their lively and indignant communication.

As space for articulation of needs is denied they return in a rationalized (re)version. Accordingly the experience of women as strange and powerful self contained bodies is collectively confirmed, only to be stored in the experience of each man, ready to be activated in other situations of confrontations with women.

\section{THE MISFITS IN THE CLASSROOMS - ON THE PERCEPTION OF PASSIVE CLASSMATES}

During the group interview on possible improvements of the education for social work in youth clubs the following passage occurred. ${ }^{9}$ It is just one example, and a fairly moderate and well argued one too, of participants talking derogatorily about their fellow students. The textual reproduction does not signal the speed of the lines or the vibrating anger of the group, nor does it catch the vehemence of the initial statement by Anna - on the factual surface she is simply stating:

Anna: "There is one thing about the club education, though, and that is that when you start, that is on the first day, and people introduce themselves ... and it happens both here and on other courses ... you often hear that people are subject to rehabilitation [i.e. being supported by labour market authorities because of physical or social handicaps KW]. And it is maybe 15 or $20 \%$, that represent, in a class, that actually is that. It's not as if there's any wrong in that, mind you, and I do agree that it's a fine thing to be social and to help a lot of people, but I do have a feeling that if you can't become anything else, or if you are unable to keep the job you once have, then you can always become a club pedagogue [Danish: Klubpædagog, the name of the un-skilled social workers in youth clubs KW]. And I can't help feeling that the education sort of falls down a bit because of that".

Kenneth: "Not just those that have a bad back, but if they have problems that cannot be combined with our profession, then I think it's wrong. And there is much debate about it around, actually!

Des: "Yes, but that is because people are so different here, and because their background is so mixed. And of course there are some that are not so used to these here things. To formulate things verbally or in writing, that is - you 
can feel that, it's all very different, and the teachers must pay attention to the differences. And sometimes you feel that it's ... a bit heavy ... there must be space for all".

Anna: "And I absolutely do agree that there must, and I would not think it wrong if it were only a few, but it's many (...) And there's nobody around to look after people who maybe have a hard time. But I do think that the general level sort of drops because of that (...)".

Kenneth: "But they are allowed in along the same lines as everybody ...".

Peter (interrupting): "No, no, I don't think so. There is a lot of people who do not have enough points, but who get in because of their background. It is basically a downgrading of our trade".

Anna: “That's my point. That's what I'm getting at. I think that the education is degraded".

Kenneth: "You get a world of problems later on, when you get out, when you have problems with yourself, and then have to work with other people who have problems. That's where it is bound to go totally wrong".

Val: 'I don't think it's acceptable. I don't think we should just live with it, for I consider our way of working an important part of the life of young people. We are there to help them, and to guide them, and to instruct them, and it simply cannot be right that there are some people who have problems themselves, and who cannot tackle their own problems, and then to go in and work with children and youngsters (...) And for anybody to just come in from the street, apply for a club job, and the get it, because we need staff. That's dangerous, I feel".

Kenneth: "I agree. It cannot be right that any number of nut-cases can get into this. It's not that they are dyslectic, it's not that. (...) You can get a diploma here even if you have a severe alcohol problem. There are people here who have really grave problems with themselves ... with alcohol or with other things ... and it's them that a lot of people want out".

Peter: "But don't people sort that out for themselves?"

Val: "No, I'm not sure, because there are some who'd say that: I need to hang on to this because I need the 10.000 kroner every month. And there's no other way to get it".

\section{Facts and Fiction}

If we look, firstly, at the factual content of the passage, of the presentation of the educational context, a number of lines are arresting: The fact that some participants 
are subject to rehabilitation is verifiably true, but the registered number is exaggerated. Another stated fact is that some people are allowed in especially because they are handicapped, which is formally and empirically not possible. A third is that any nutcase can get in from the street and that you can get a diploma in spite of alcoholism, intimations that are basically unfounded..$^{10}$ On the whole the college is given little credit: It has few resources, it lets people in against rules, it accepts general dissipation, and hands out diplomas at random! This contrasts heavily with the explicit satisfaction with the education evident in other parts of the text.

So the impact of the passage is that the group - as opposed to the college - is concerned with a potential dilemma well known in education, namely how far a given education should accept participants that need special attention for social and health reasons, and that it is so concerned that some exaggeration is needed to convince the interviewer. The group is aware of this dilemma. Several lines meet with envisaged contradictions that they are discriminating people who do not deserve it, i.e. the bad backs and the dyslectics. The concern is on behalf of the status of the education, of the profession, and of the children and youngsters in the clubs.

Now, skilled and professional labour is actually in great demand in the Danish health and social sector. It is an acknowledged fact that there are "too many unskilled pedagogues" at work not only in clubs, but also in day care. ${ }^{11}$ Furthermore the club sector by tradition recruits non-professional staff, and so it is vulnerable to general stigmatisation when staff problems occur - which invariably they do, as Kenneth confirms. So the arresting point here is not so much that the group points to a problem, but that in the public and administrative eye they are themselves the very population that is problematic in the sense that they are not formally qualified for their - societally important - job of socialisation and integration. That is why Danish municipalities demand that they complete the education programme that is the subject of our interview. Whether the individual participant suffers from a bad back or is recovering from drug abuse, whether he or she is in education - and working in the youth club - because he or she fell out of university, because the building industries are down or hairdressing is not much of a business these days these facts are immaterial - both in the public eye, in the bureaucratic sense and as far as the educational measures are concerned. And contrary to the assumption of the group there is no documented covariance between rehabilitation, dyslexia, alcoholism and having problems with oneself. ${ }^{12}$

The concluding line, Val's accusation that the rehabilitating colleagues are strictly instrumentally, economically, motivated, is also strange. For it is generally agreed that more or less everybody in this education are dependent on upholding their income while they qualify. The education is designed for such people, for adults, with adult lives and obligations.

The characterization of the club pedagogue's task - as "helping, guiding and instructing" (Val) - is noticeable: It is true that working with the young is societally important,and that youth need reliable adults! But social advisors, school teachers and other professional groups would smile, to say the least, at the club pedagogue's 
ambitious self-understanding. Youth clubs do work with fringe groups, but much everyday life in youth clubs comprise a number of relaxed leisurely activities. Furthermore in the Danish context the references to the work as "profession" (Kenneth) and "our trade" (Peter) is peculiar. They signal a well defined line of work, social recognition and standards of quality - in short: professionality. ${ }^{13}$ Actually the culturally established profile of the "club pedagogues" is that of the informal, comradely and loyal companion - undisturbed by professional distance, defying control and disciplinary dimensions of the job. This collective understanding of the sector is confirmed throughout the present project, and although it may be said to make a virtue out of necessity, it appears well founded in the subjective experience of the staff. If this syndrome is perhaps also nurtured by subjective and objective inferiority, it is at least a popular one ... but it is remarkably absent in this passage. Here we meet professional concern only.

One interesting feature of the dialogue is the way factual corrections are turned around and used to opposite ends: The group denies the fact that the rehabilitating colleagues are allowed in along the general rules (as suggested by Kenneth) and it refutes the possibility that they might themselves be capable of assessing their competence (as imagined by Peter). Both attempts at modifying Anna's initial definition of the problem are used to further degrade the colleagues.

Finally the group builds consistent argument that people who "have problems with themselves", i.e. who are psychologically unstable, should not work in the caring professions, concluding that they are only in it for the money, anyway. The preoccupation with the psychological resources is a valid and recurrent debate all over the social and health sectors, and it does possess its own relevance in this short-term educational programme. But there is little, if any, reason that this general problem should arise in the context of the discussion.

So even at the surface level, where the text is confronted with the reality it refers to, the text has little value of information. In a positivist sense the group is not reliable. On the other hand the group is remarkably at ease with itself, it is in relative agreement - it is obviously telling us something important.

\section{Communicative Dimensions}

So how does the group go about it? Which features in their way of talking and which figures of speech convey the message to us? As above, the lines are spoken rapidly, with a high level of dedication, and there is a generally positive and corroborative atmosphere. People are eager and responding, almost echoing, and the energy grows steadily throughout the quoted passage.

As it turns out Anna's opening statement sets a theme, and also launches a pattern of formulation that are kept up by the group during the paragraph. Anna repeats a lot. She uses a number of parallel, slightly droning sentences, as well as literal repetitions. She feels, even if she allegedly doesn't want to - thus calling for explication of this conflict between emotion and rational argument. The theme is 
that of the others, developed as a definition of intruders. The imagery of intrusion is supplemented by that of the education falling down, and the general framework of right and wrong is introduced.

The intrusion is defined by the "wrong" presence of the others. Their getting into the introduction is echoed all through: they make the space heavy, they are allowed in wrongly by the system, they go in the work, and they get into this, until at last they are wanted out - of the education, to prevent them from getting out in the workplaces.

Anna's perception is that the education "falls down a bit" as if the education might fall on her and bring her down. This is no error of translation, she actually uses this slightly awkward, very concrete image. Combined with the inevitability of the feeling the fear of falling is frightening. "A bit" is a paradoxical colloquialism, literally modifying, but substantially augmenting. It is echoed in the space getting "a bit heavy" (Des), and in the "sort of" dropping level (Anna herself). Finally the image is qualified in the "downgrading of our trade" (Peter) and the "degrading of the education" (Anna herself).

The theme of right and wrong is paradoxical from the outset: Anna distinguishes in the peculiar way that something is wrong (the number of participants in rehabilitation), which there's "nothing wrong in" because it's social and helpful and (therefore) right. It is within this paradoxical framework that she must modify her statement, she "can't help" feeling, despite herself. In her second remark Anna reiterates both structure and content of the first: She confirms her original "nothing wrong", assessing that "absolutely" must there be space for all - only not for all, because there are too many. She accelerates the discomfort by denying her own reassurance of the right, that she thinks wrong, you cannot do that much right, too much right makes wrong, and she substantiates her point by alluding to the (too small) resources of the college, again ending up in a down falling image, this time of the education dropping. The wrong is first substantiated by Kenneth, modified (into difference) by Des, enhanced by Kenneth (into totally wrong), civilized as well as dramatized (into not acceptable as well as downright dangerous) by Val, and confirmed (it cannot be right) by Kenneth, who also elaborates qualitatively as well as quantitatively on the danger: the intruders are nut-cases, they come in any number, their problems are severe and really grave, and the problem is alcohol as well as other things, intimating drug problems. The culmination of the definition of the wrong is the explication of the attitude of the others. They are dishonest, they are in the education on pretence.

\section{Do Not Degrade Us!}

Cris-crossing these consistent figures is the emotional presence of the "we" of the (insider) group as called upon by Anna's anxiety, as opposition to the others, who represent the explicit danger of the club-pedagogues being considered of no value ("if you can't become anything else") - a fear well-founded in the current hierarchies of the social and health labour market, a much wider problem with no 
direct connection to a possible number of misfits in the education. This is made explicit again when Anna - happily: "That's my point! That's what I'm getting at!" answers Peter's "they are let in", where she also changes the "downgrading of the trade" to the "degrading of the education". She is herself part of the education, she is indeed within it in the very interview situation, so if the education is degraded, she is herself degraded. The unconscious thematic collusion of the group is: We do not want to be degraded. And at this point the more vicious attacks on the others (Kenneth's remark and Val's denunciation of their morals) have become legitimate. And the somewhat pompous sketch of our own importance in "helping, guiding and instructing" falls into place.

So the real danger is one facing the group itself, and the unconscious danger is that the degradation might be justified. After all "problems with oneself" and a fair amount of daily alcohol intake are not uncommon - neither with the population in general or with the low-skilled segment with an unstable labour market position that the group represents. Although in the interview situation the individuals come out as winners, there is no reason that they should not be as ambivalent facing the challenges of their job of social work as anybody else, and their labour market carriers are probably as mixed. ${ }^{14}$ In structural terms the group represents one layer or level in a Chinese box, where income and cultural status form the objective foundation of individual and collective inferiority, substantiated by the imagined shortcomings of other professional groups. ${ }^{15}$

So as a result of the interview we have gained two results, neither of which are directly relevant to the evaluation project: One is that it takes very little to bring out an intolerant and aggressive attitude towards people with social problems in the club pedagogues to be - the exact opposite of what the educational impact should ideally be, and one which seriously questions the general suitability of the unskilled social workers to their jobs. I.e. the group manages to produce the exact opposite of their more or less conscious intention. Another is that the club pedagogues-to-be are in serious need of recognition. Below I shall discuss how and why the educational setting and the position of being a student may contribute to these two states of mind.

\section{INDIVIDUALS, TEXTS AND GROUP DYNAMICS}

The individuals who spoke the lines quoted were brought together in their special capacities as participants in an educational setting that was being explored and evaluated. They brought into the research setting not only their shared experience of the educations, but also the general experience of their everyday life and their respective life histories. In this respect they are representative ${ }^{16}$ of the unskilled populations that in current years are more or less willingly training or retraining for the changing and increasingly qualifications demanding labour market. Their labour market experience is a mixed bag: this segment of the labour force is the one to immediately feel ups and downs of trades and the general economy. Participants' 
experience comprises a number of contradictory motivations. The jobs headed for are much wanted, if not for their content then for the income. The road to get there is, however, paved with a number of imposed regressions, the structural position of a pupil perhaps being the most basic and at the same time the most challenging.

So the general background of experience is contradictory - jobs wanted, training unwanted, followed by training accepted, and infantile position unwanted. ${ }^{17} \mathrm{We}$ are not surprised that there is an explicit need to let out some steam of aggression, for these adult pupils have surely had a number of reasons to be angry along their ways, and have not been offered appropriate arenas for voicing their experience and putting it into words.

The group communication will implicitly and sometimes explicitly appeal to each participant to search emotionally and cognitively for the shared experience of the group. ${ }^{18}$ Of course the experience of the research setting is immediately shared, as is the implicit subjective pressure to contribute. The interview situation bears some structural resemblance to the teaching, which holds its own kind of pressure, and the teaching in its turn refers to the work situation, which holds another kind of pressure. It may even be argued that the interplay between these levels of experience of pressure is in itself anxiety provoking and will produce regressive resistance. So if there is anxiety around it is sure to be exposed, and as we have seen in the texts, it does, and it is managed by means of collective rationalization. ${ }^{19}$

So voicing shared experience referring to any of these levels invariably brings about qualities of perception that cannot be understood in terms of the factual events referred to only. The challenges of social work and dealing with patients have long ago activated emotions, strategies of action and understandings from other phases of the life course, from family settings as well as from other workplaces. In the communication a gradual and intuitive selection of experience suitable in the group takes place, and emotional qualities and intellectual insights are attributed to the common production of meaning. This does not happen randomly, but not in a purely rational manner either. Contributions are formed in a subjective navigation between the reservoirs of individual experience and the theme perceived developing in the group. In this respect the research setting actually reproduces a characteristic of everyday life communication, where the attitudes and emotions of people are often not articulate until they are offered a communicative arena, until they are voiced in a social situation. The group thus develops its own explicit meaning, drawing on dimensions of experience, and indeed formulations, from the individual participants, who in their turn have contributed, not what they are, who they are, or what they think, but what this setting and communication allowed them to feel, remember and articulate - and avoid. The meaning developed by the group is not simply the sum of the attitudes and opinions of the participants, nor are the participants victims of external group dynamics. The group produces a unique and original text that communicates shared experience, not exhaustingly so, but relevant and carefully voiced dimensions of experience. 


\section{RECOGNITION, AGGRESSION AND EDUCATIONAL RESULTS}

The two empirical populations have produced texts that explicitly and implicitly voices the need for personal and professional recognition by superiors and by society. They have also "texted" a professional concern - for the well-being of psychiatric patients and for the reputation of the education for social pedagogic work in clubs thus legitimizing not only their demand for recognition, but also their apparent emotional state of readiness to perceive degradation and humiliation.

In both cases, however, the groups verbalized their messages in a roundabout manner by abusing a specific population of others, indeed they collectively constructed the female nursing staff and the rehabilitating colleagues respectively, not only as less able populations, but as morally corrupt as well. The images produced and confirmed each correspond depressingly well with a number of cultural cliches active in popular or populist political rhetoric and in everyday folklore. As recognizable figures they serve to simplify and thus make bearable the complex and multitudinous experience of everyday life, and as organizers of subjective collective energy they contribute powerfully to corrupting political civilization and gender equality. It is safe to say that the attitudes texted above are not the intended outcome of the respective training programmes. They have certainly nothing to do with neither the formal curriculum nor with the intended communication of workplace culture or general political implications of being public sector social service staff. They even disavow the professional ethos that they serve to establish in the texts.

So have the educations been counterproductive? Is the educational outcome that poor? And are the individuals so politically blind (labelling socially deprived groups) and so male chauvinist?

Hopefully not. My exposition of the regressive images in the collective unconscious of the groups is on the one hand a research produced artefact that on the other hand - exposes a potential of subjective energies, organized within the framework of the consciousness of everyday life (Leithäuser, 1977). A general cultural disposition to employ reductive schemes of understanding in complex and challenging situations is reproduced. The interpretation has focussed on the frightening aspects of the collective subjectivity - with good reason, I should think but the texts themselves comprise reference to the contradictions reacted to. There is a framework of ambition of being and doing "right" in the club pedagogues' discussion and beyond the aggression of the men in the psychiatric hospital we can actually detect some sound observation of a routinized and (too?) highly gendered workplace culture.

So the scapegoat figures of munching women and morally corrupt colleagues are also inversions of a general humanist and/or professional ethic - the claim that education and social work should be for the benefit of the users - children, youngsters, patients, etc. In fact random elements of such ethics are employed to construct the villainous images. And in present day institutionalised and bureaucratic public sector such ambitions, however fragmented they stand, are no irrelevant agenda. 
My general line of arguments has been that the interplay between lacks of recognition at different levels of experience is decisive in producing the defensive reductions. So the experience atclassroom level does come into it.

So what characterises the classroom experience: A double agenda of accepting to be a pupil and a curriculum of welfare state legislation, psychology, pedagogy, cultural studies, etc. - very much about the very situation that is reacted to, but in both training programmes, in abstract and general terms. Indeed the men in the hospital faced a number of physics and chemistry lessons at the level of 7 th grade, but that was difficult enough. And although teachers strive to meet the subjective experience of the work they are qualifying people for, they work within a set of rules describing the context of the education in terms of subjects and disciplines, not as experienced problems.

In educational terms these analyses thus point to the relevance of problemoriented curricula, and to the need of explicitly reflecting the background experience and the subjective motivations of participants within the framework of education. It also reminds us that teachers should respect that subjective motivations are only one version of the multitudinous sensations and perceptions that adults possess aggression may be an integral part of regressive defences as well as progressive orientations.

Finally, as stated at the outset of this chapter, a number of the mixed and functionally inappropriate motivations are in fact embodiments of the economic and societal paradoxes that constitute everyday life in and around education: Adult pupils, soldiers in nursing, men in women's jobs - are empirical evidence of contradictory demands of modernization, rationalization and labour market development. If they appear irrational, history is irrational, and a rational appropriation process will reflect it.

\section{A REMARK ON THE METHODOLOGY}

The general framework of my interpretation is that of a psychoanalytically oriented social psychology, that acknowledges preconscious and unconscious dimensions and dynamics in everyday life communication. It also appreciates participants' life history experience, the everyday life experience and the interplay between these subjective reservoirs.

In contrast to the well known clinical psychoanalysis, this approach is concerned with general cultural patterns of subjectivity, where a potential of politics of repression as well as of liberation is stored. Of course collective subjectivity is constituted by the interaction of individuals, and by the collusion of individual drives and dispositions. It might, for example, be productive to see the aggression of the men in the hospital as collectively re-iterated scenes of primary socialization, where identifications with mother and father respectively comprised not only "becoming like", but also counter-positioning, fights and ambivalent possession. For the men are under regressive pressure, they are infantilised and denied their status (and identity) as men. It is likewise interesting to consider the discriminating and rigid 
appropriation of "right" by the club pedagogues as an identification with a mighty if abstract aggressor - in momentary need of more specific, tangible and realistic ideals. Such deepening of the current analysis is indeed possible, but the procedure might create the impression that I was aiming at a redefinition of the educational setting into a form of collective therapy.

Although I am sure that educational settings are often the arenas of subjective liberation, including liberation from inner compulsions, the therapeutic fallacy (Alheit, 1994) is not mine. The primary socialization of participants is only relevant in this context insofar as it is activated and becomes decisive in the interaction, in the production of the meaning of everyday culture - including that of education. In that context the energies and search processes of participants must be respected - indeed they cannot be substantially changed without counterproductive effects. They must find their own - devious - ways (cf. Weber, 1995).

Learning and socialization is always a progressive-regressive process, and it always activates the inner resources of the learner. So the focus of the educationally relevant analysis is on the interaction with reality and on how it is voiced.

So a social psychology that draws on the tradition of psychoanalysis faces the theoretical challenge of understanding subjective energies not as natural instincts or fateful drives, but as energies organizing reality. This is the ambition of the German social psychologist Alfred Lorenzer, who defines drives with a view to societal and interactional logics meeting with the individual in primary and secondary socialization, shaping subjectivity but also being changed by the specific ways in which the logics are appropriated (Lorenzer, 1970, 1972). The concepts of ambivalence as defined by the Hungarian psychoanalyst Sandor Ferenczi: inner ambivalence stems from the contradictory qualities of reality, not from the confrontation of libido and thanatos (Ferenczi, 1972), as well as the whole tradition of object relations theory (e.g. Winnicott, 1987) point to the same concern for the outside world. With Lorenzer, however, it is an explicit point that unconscious processes themselves are not just products of individual repression, but societally produced ones. Life history is thus an ongoing process of socialization, not just an adaptation of individuals to reality, but a dynamic continuation of society and culture as such: Subjectivity is society in a specific historical and social mediation of individual sensation - bodily, emotional, cognitive perceptions - with language as the primary medium. The approach has been succesfully developed into a psychoanalytically oriented understanding of culture in general, comprising not only literature and media analyses, but also understandings of architecture, physical space in general, etc. (Lorenzer, 1986). Theorizing everyday life is a well established tradition in cultural studies and sociology, and the very concepts of every day life is developed into a theory of late modern consciousness by Thomas Leithäuser, who sees the different sections of everyday life as arenas of experience, adapting to necessities, repressing socially illegitimate sensations and reactions as well as developing wishes and ambitions. Leithäuser's concept of consciousness of everyday life point to the fact that attitudes and opinions may beunderstood as pragmatic and situated - individual or collective - subjectivity, thus 
questioning the established concept of identity, as well as indeed the validity of any positivist registration of attitudes. Together with Birgit Volmerg and the Institute of Psychology and Social Research in Bremen the approach has produced a number of empirical studies, comprising workplace experience and experience in public space (Volmerg et al., 1986, 1994, Leithäuser, 1999).

Integrating a Marxian analysis of society - the separation of private and public sphere and the logics of production and reproduction - with psychoanalytical social psychology, Regina Becker-Schmidt et al. have produced a number of analyses of women's experience in work and family life. Becker-Schmidt applies the Ferencian concept of ambivalence as well as concepts of identification processes to the field of girls' and women's lives, and she contributes substantially to a gender-specific and historically sensitive understanding of socialization (e.g. 1995, 1998; see also Chapter 4, this volume).

The brief account of the approaches hardly do them justice, but they each served as inspiration to the analysis presented above. The theorizing of learning settings gains by a societal dimension that can see actions and attitudes, not as individual fallacies or shortcomings, but as valid reactions to complex and partly invisible logics. Before concluding this chapter I shall elaborate somewhat the underlying understanding of our media of communication - language.

\section{LANGUAGE GAMES AND INTERACTION-FORMS}

Language as an integral dimension of interaction and bodily experience has been theorized by Alfred Lorenzer, who sees the dynamics of subjectivity - of inner nature - and societal structure as authentically experienced bodily interactions, established as interaction-forms. They constitute the basic socialization, and they are progressively differentiated and refined as language is introduced. Only language also serves to render some interaction-forms acceptable, while others remain as bodily perceptions, pre-verbal - but none the less psychologically active. The basic epitome of the interaction-form is the mother and child, the dyad - not only because this stage in socialization holds importance, but also because it serves to illustrate the dialectic of refinement and deprivation that socialization is about. No verbalization, no establishment of symbolic interaction, takes place without leaving something behind, organizing perceptions, leaving some out and "forgetting" them systematically. Pre-verbal interaction forms melt into the symbolic ones as interaction-forms and language relate. Lorenzer ses this process as a potential for later reflected experiments (in the psychoanalytic sense: Probehandlungen) of action and expression.

Lorenzer's ambition is to theorize language, interaction and bodily experience in the context of their mutual societal settings and functions. The concept of language game, which stems originally from Wittgenstein, situates language practically and societally. The language game is a complex unity of the actual use of language, its practical functions and the general understanding of its life world. It mediates 
subjective and objective structures, and its genesis is indeed the constitution of the relation between individual and society. Language and consciousness are integral parts of societal praxis, and language games are accordingly the medium of subjective structuring of reality. In this sense individual subjectivity is societal from the outset.

In an intact language game the agents share pre-verbal interaction-forms as well as its specific verbalization, in language becoming a symbolic interaction-form - in short: that agents understand each other and empathically share explicit and implicit meanings.

Lorenzer introduces the concept of disturbed language to understand the process of the "re-division" of language games. Once accomplished competencies of symbolization - putting subjective structures to language - may, in specific situations, that recalls and activates inner conflict, cease to work. The capacity of expressing subjective experience is lost facing the confrontation of contradictory and irreconcilable interaction-forms. Pre-verbal interaction forms that have never been integrated into the language games at all may well be part of such conflict, although they are systematically left over to the unconscious. In such cases language is unfounded in experience, the words stand stripped of authentic meaning. Lorenzer uses the concept of sign about this language with no foundation in interaction-forms. Accomplished symbolic interactions may also be broken up for psychodynamic and/ or societal reasons, the word stripped of its symbolic meaning, but still representing dynamic inner scenes - which, in their turn, may be activated without access to relevant means of communication.

Language games will not only echo interest and power relations in the social situation, they will also develop meanings of their own, register and comprise factual as well as implicit cultural and psychological meaning. They are dialectical unities of the use of language, everyday life as it is in fact lived practically, and the attitudes, opinions and ideologies it develops and makes use of. In the research situation we have "only" the words, but if we look at the communications in terms of a language game we have also a symbolic life world.

In the language game subjective structures are mediated with reality, with social and societal structures. When the appropriation of reality demands emotional or cognitive accommodation the language becomes vague, which gives the communication of everyday life its well known specific quality of implicit congeniality, of indefinite allusions that comprise a variety os different sensations and recollections. To each individual words and concepts possess an aura of implicit meanings founded in earlier experience, and in interaction and communication these meanings are sorted out and established as new collective formulations, that merge with the general cultural reservoir - confirming and changing culture. In this process factual information and authentic experience may find words - become symbolized but as we have seen they may also be censored, withdrawn, only to sink back into the pre-verbal consciousness of individuals and institutions.

The club pedagogues certainly go through a process of negotiating and sorting out the relevant phrases before their implicit aggressions are finally focussed on the 
"danger" and dubious morals of the rehabilitating colleagues, whereas the men in the psychiatric hospital immediately share both a vocabulary and a cultural image of femininity. The former are bringing together vague anxieties stemming from number of different settings, whereas the latter have recently faced much the same challenges, which they can therefore readily communicate. Maybe the common gendered experience contributes to the immediate collusion in the male group. The cultural cliche of "cunt prat" actually brings together the subjects of the women's talk with the otherwise tabooed sexual connotations - not only implicit in the men's perception, but certainly in the workplace culture as well as in society in general.

On this background we may look at the text as a frozen version of specific interaction. We may look at the referential level, which is immediately understood because words refer to recognizable objects and situations, and where the cultural connotations are shared. As I have shown even this level raises a number of questions: the texts each possess a referential value that is unknown to the interviewer or discussion leader, and which he, in his turn, tries to come to terms with - as Steen, who does not personally share the emotional content of the communication, translating into the more general concepts of workplace culture. Of course the interviewer may simply get new information, but in the texts above, we are given to wonder, because the information we get does not agree with our existing knowledge of the field: We are cognitively as well as emotionally aroused. We think we know, for instance, that the administrators of the club education are not reckless - and we are disturbed by the prospect of alcoholics in social work. We react on behalf of the general cultural framework: this cannot or should not be so. ${ }^{20}$

So we move on to other potential sources of information in the text, to the communicative dimension and to be empathic on the communicative level as well: How does the mode of communication add or detract from the phrases, and which figures of rhetoric are employed?

By confronting these levels of reading, answering the research question: How do they talk about what? In this process new structures of subjective meaning, embracing implicit meanings as well as explicit ones, are formed, and we approach a motivational and perhaps an experiential, perceptual understanding.

Such understanding might inspire adult education to some abstaining from directing the learning processes towards specific curricular goals, and to a critical reflection of the relation between teaching and learning in general. People learn what they want to learn - and their rich ambitions of being recognized themselves as well as changing the world for the better are much easier developed if they are allowed to - and supported in - sorting out their ambiguities and reflecting on them.

\section{NOTES}

1 The evaluations were designed as theory based and qualitative, and the empirical material produced within the research context of the "Life History Project", a long term project on the subjective interplay between adult education, every day life and life history (Weber, 1997c, 1999b; Andersen, 


\section{K. WEBER}

2000; Salling Olesen, 2000a, 2000b). The Danish evaluation reports are Nielsen and Weber (1997), Weber (1997a), Lund and Weber (2000), as well as Weber (1997b) and presentations of analyses in English are Weber (1996, 1998, 1999a).

2 Besides myself: Research assistant cand.mag. Steen Baagøe Nielsen (now associated professor at Roskilde University), and research assistant cand.pæd. Uffe Lund, presently an education officer at the pedagogues' union in Denmark.

3 The evaluations were financed by the County of Western Seeland and by the Ministry of Social and Health. Each in their way they were characteristic measures of the current transformation of the public sector in Denmark, that aims to change the traditional welfare state into an so-called "responsive state" - in this case in the sense that the public labour force must be (made) flexible. This theoretical and political discourse falls without the scope of this chapter, see, however, Weber (2001a).

4 The concept of "research subjects" referring to the population of informants and participants stem from Hollway and Jefferson (2000). It signals the dynamic and autonomous status of the people involved as opposed to the status of objects under positivist scrutiny.

5 The methodological implications of this double bind is a research field in itself. Likewise the different modes of text production, the informing group interview (cf. e.g. Kvale, 1996) and the thematized group discussion (cf. Cohn, 1976; Mangold, 1960; Leithäuser \& Volmerg, 1985) represent separate fields of interest. In the present context, however, only the fact that the texts are group produced, and the fact that they comprise culturally significant outbursts of aggression, are looked into.

6 The group discussion leader is Steen Baagøe Nielsen, and the passage is translated from the evaluation report (see above, pp. 139-140).

7 Direct translations of the Danish "kussepladder" and "agurkesnak", both original and striking verbal innovations of a highly derogatory nature - from other group discussions of the men in the project.

8 This is actually changing in Denmark. The medical profession presently recruits a majority of women, but firstly this has not yet changed the work-places, and secondly it is still true that executive positions are held mainly by men. I.e. a horizontal gender barrier has been moved, but a vertical one remains.

9 The interviewer is Uffe Lund, and the passage stems from the background material of chapter 5 of the evaluation report (see above, p. 57 ff.).

10 The verifications of these facts with the administrative authorities of the college is solid. The identification of factual faults or inconsistencies in the communication is not motivated by any drive to "correct" things, but is a means to identify the energy and motivations present in the group. Of course evaluators and researchers should not communicate gossip and rumour as such, but in this approach gossip and rumour communicates something important besides their factual irregularities. So we take it on face value, we test it against the reality that we know something of, but which we may also learn about.

11 This is due to the educational policies of the liberal government in the 80 'es, which restricted access to human service training and education considerably.

12 In fact some of the texts in this project could support the opposite thesis: A number of the rehabilitating colleagues appear lively, intelligent and well motivated participants with a realistic attitude to their handicap. Whereas some of the university drop outs could be said to signal problems of self esteem, and some of the skilled workers to manage the shift from production to social work less than well. But these are mere assumptions, associations in the research team, who have obviously been severely provoked by the group's unanimous problem identification. In it inherent in our approach not to censor such associations, but to register them, and to confront them with the text. You can say that at first we serve as a screen on to which the allegations of the group are projected. And next we react, and serve as a complementary mirror. Neither the construction of the group nor the associations of the research team are "true" in the literal sense, but they each constitute possible perceptions and dimensions of experience.

13 Not even the professional educations of $3 \frac{1}{2}$ or 4 years' duration - such as those of pedagogue, nurse or school teacher - can claim proper professional identity in the strict sociological sense, and when they try current modernization quickly get the better of them with further demands of flexibility and employability (Weber, 2001a; Salling Olesen, 2000b). 
14 The life history of the group was not focussed on in the interviews. But we know what they are doing: Anna's task in the leisure centre is in the kitchen, where she bakes with the school children every afternoon; Kenneth dropped out of technical college and has made a career of working in the national organization of youth clubs, thus so far making further education unnecessary; Des is an immigrant with ten years of unskilled social work behind him, specialising in computer games and music; Peter is young and has no education or labour market experience other than that in the social project he is employed in; Val has an education as a teacher of textile work, i.e. she is working beneath her status, but indeed she does run the sewing workshop in her workplace.

15 Thus traditional profiling school-teachers-pedagogues, pedagogues-unskilled staff, unskilled staffunemployed, etc. are well known. Of course they have their objective foundation in different status of the societal tasks, of income and status, but they are often voiced with more vigour than the objective differences would vouch.

16 This is not a question of statistical reliability, although by age and labour market position the populations may well mirror their social strata. Within the context of the club education the groups have been composed with a view to comprising the most characteristic empirical profiles - genderwise and by educational background. The men in the hospital are simply those allocated from the local unemployment authorities, and so they represent the profile of qualifications demand in Western Seeland. Both populations are plausible examples of unskilled adults in education. For a discussion of validity in qualitative research see Kvale (1991) and Altheide and Johnson (1998).

17 At an individual level, with each adult man or woman it is of course much more complex. Some adults actually want the training, but not the job. Class and gender form different foundations for handling the dilemma. But in a strategy of theorizing the motivational conflicts one has to simplify, in this case by stating a common structural dilemma.

18 The underlying references here are the tradition from Pollock onwards, the group therapy (Foulkes) and communication in groups (Bion).

19 The analysis might at this point be extended in terms of exposing institutionalised defence mechanisms, cf. e.g. Menzies-Lyth.

20 Of course the individual characteristics of the researcher come into this process, both in the face to face interaction and in the interpretation. So we should reflect our idiosyncrasies and, our loyalties as well as our theoretical perspective in terms of transference and counter-transference. For a discussion see e.g. Hunt (1989) and Andersen (2001).

\section{REFERENCES}

Alheit, P. (1994). The biographical question as a challenge to adult education. International Review of Education, 40, 283-298.

Altheide, D. L., \& Johnson, J. M. (1998). Criteria for assessing interpretive validity in qualitative research. In K. D. Norman \& S. L. Yvonna (Eds.), Collecting and interpreting qualitative materials. London: Sage Publications.

Andersen, A. S., Andersen, L., Dybbroe, B., Hutters, C., \& Weber, K. (Eds.). (2001). Bøjelighed og Tilbøjelighed. Livshistoriske perspektiver på laering og uddannelse (3rd Report from the Life History Project). Roskilde: Roskilde University Press.

Andersen, L. (2000). Telling modernization: Three voices. life history, gender and the discourse of modernization (Paper No. 8). Roskilde: Life History Project, Roskilde University. Adult Education Research Group.

Andersen, L. (2003). When the unconscious joins the game: A psychoanalytic perspective on modernization and change. Forum for Qualitative Social Research, 4(3), Article 26.

Becker-Schmidt, R. (1995). Von Jungen, die keine Mädchen, und Mädchen, die gerne Jungen sein wollten. Geschlechterspezifische Umwege auf der Suche nach Identität. In R. Becker-Schmidt \& G.-A. Knapp (Eds.), Das Geschlechterverhältnis als Gegenstand der Sozialwissenschaften. Frankfurt: Campus.

Becker-Schmidt, R. (1998). Trennung, Verknüpfung, Vermittlung: Zum femnistischen Umgang mit Dichotomien. In G.-A. Knapp (Ed.), Kurskorrekturen. Feminismus zwischen Kritischer Theorie und Postmoderne. Frankfurt: Campus. 


\section{K. WEBER}

Cohn, R. (1976). Von der Psychoanalyse zur themenzentrierte Interaktion. Stuttgart: Klett-Cotta.

Ferenczi, S. (1972/1926). Das Problem der Unlustbejahung. In Schriften zur Psychoanalyse. Frankfurt am Main: Fischer.

Hollway, W., \& Jefferson, T. (2000). Doing qualitative research differently. Free association, narrative and the interview method. London: Sage Publications.

Hunt, J. (1989). Psychoanalytical aspects of fieldwork. Qualitative research method series, No. 18. London: Sage Publications.

Kvale, S. (1991). Issues of validity in qualitative research. Lund: Studentlitteratur.

Kvale, S. (1996). Interviews. An introduction to qualitative research interviewing. London: Sage Publications.

Leithäuser, T. (1977). Formen des Alltagsbewusstseins. Frankfurt: Campus.

Leithäuser, T. (Ed.). (1999). Sicherheit im öffentlichen Raum. Alltägliche Gewalterfahrungen im Stadtteil. Sonderheft Arbeit und Politik. Bremen: Akademie für Arbeit und Politik.

Leithäuser, T., \& Volmerg, B. (1985). Psychoanalyse in der Sozialforschung. Eine Einführung am Beispiel einer Sozialpsychologie der Arbeit. Opladen: Westdeutscher Verlag.

Lorenzer, A. (1970). Sprachzerstörung und Rekonstruktion. Vorarbeiten zu einer Metatheorie der Psychoanalyse. Frankfurt: Suhrkamp.

Lorenzer, A. (1972). Zur Begründung einer materialistischen Sozialisationstheorie. Frankfurt: Suhrkamp.

Lorenzer, A. (1986). Kulturanalysen. Psychoanalytische Studien zur Kultur. Frankfurt: Fischer.

Lund, U., \& Weber, K. (2000). Kort og godt? Laring, kvalificering og effekt $i$ klubuddannelse og klubarbejde. Adult Education Research Group, Roskilde University.

Mangold, W. (1960). Gegenstand und Methode des Gruppendiskussionsverfahrens. Frankfurt: Europïsche Verlagsanstalt.

Nielsen, S. B., \& Weber, K. (1997). Jagten på den mandlige omsorgskompetence. Adult Education Research Group, Roskilde University.

Salling Olesen, H. (Ed.). (1995). Adult education and the labour market II. Papers from the 2nd Seminar of the ESREA research network, Strobl, Adult Education Research Group, Roskilde University \& Bundesinstitut für Erwachsenenbildung St. Wolfgang, Austria.

Salling Olesen, H. (Ed.). (1998). Adult education and the labour market IV. Papers from the 4th Seminar of the ESREA network on adult education and the labour market, Dubrovnik, Adult Education Research Group, Roskilde University.

Salling Olesen, H. (2000a). Experience and life history life history project (Paper No. 9). Adult Education Research Group, Roskilde University.

Salling Olesen, H. (2000b). Professional identity as learning processes in life histories. Journal of Workplace Learning, 13(7-8), 290-298.

Salling Olesen, H., \& Forrester, K. (Eds.). (1999). Adult education and the labour market V. Papers from the 5th Seminar of the ESREA research network, Dubrovnik, Roskilde University Press, Roskilde.

Salling Olesen, H., \& Rasmussen, P. (Eds.). (1996) Theoretical issues in adult education. Danish research and experience. Roskilde: Roskilde University Press.

Volmerg, B., Senghass-Knobloch, E., \& Leithäuser, T. (1986). Betriebliche Lebenswelt. Einer Sozialpsychologie industrieller Arbeitsverhältnisse. Opladen: Westdeutscher Verlag.

Volmerg, B., Leithäuser, T., Neuberger, O., Ortmann, G., \& Sievers, B. (1994). Nach alle Regeln der Kunst.Macht und Geschlecht in Organisationen. Frankfurt: Kore.

Weber, K. (1995). Learning processes in trade union education. What do unskilled women actually learn? In H. Salling Olesen (Ed.), Adult education and the labour market II. Adult Education Research Group, Roskilde University \& Bundesinstitut für Erwachsenenbildung St. Wolfgang, Austria.

Weber, K. (1996). Experiencing gender - And a case of masculinity and social work. In H. Salling Olesen \& P. Rasmussen (Eds.), Theoretical issues in adult education. Danish research and experience. Roskilde: Roskilde University Press.

Weber, K. (1997a). SSA - mand! [Social and health assistant - Man!]. Adult Education Research Group, Roskilde University.

Weber, K. (1997b). Køn, klasse og subjektivitet. Om erfaringsbegrebet i uddannelsesforskningen. [Gender, class and subjectivity. On the concept of experience in educational research]. In K. Weber 
(Ed.), SSA - mand! [Social and health assistant - Man!]. Adult Education Research Group, Roskilde University.

Weber, K. (Ed.). (1997c). Life history, gender and experience. theoretical approaches to adult life and learning (1st report of the Life History Project). Roskilde University, Adult Education Research Group.

Weber, K. (1998). The hunt for the masculine competence for care. Qualification between labour market integration and feminization? In H. Salling Olesen (Ed.), Adult education and the labour market IV. Roskilde: Adult Education Research Group, Roskilde University.

Weber, K. (1999a). Insights into necessities ... In H. Salling Olesen \& K. Forrester (Eds.), Adult education and the labour market $V$. Roskilde: Roskilde University Press.

Weber, K. (1999b). Concepts of life history and biography: Understanding lifelong learning? (Paper No. 4)., Life History Project). Roskilde University, Adult Education Research Group.

Weber, K. (Ed.). (2001a). Experience and discourse (2nd report from the Life History Project). Roskilde University Press.

Weber, K. (2001b). Brok, brok, brok - om hverdagsliv, livshistorie og ambivalens i læreprocesser [Nag, nag, nag - On everyday life, life history and ambivalence in learning processes]. In A. S. Andersen (Ed.), Bøjelighed og Tilbøjelighed. Livshistoriske perspektiver på laering og uddannelse (3rd Report from the Life History Project). Roskilde: Roskilde University Press.

Weber, K., Nielsen, B. S., \& Salling Olesen, H. (Eds.). (1997). Modet til fremtiden. Inspirationen fra Oskar Negt [Courage for the future. The inspiration from Oskar Negt]. Roskilde: Roskilde University Press.

Winnicott, D. W. (1965/1987). The maturational process and the facilitating environment. London: Hogarth. 